\title{
Laboratory studies of ice formation pathways from ammonium sulfate particles
}

\author{
M. E. Wise, K. J. Baustian, and M. A. Tolbert \\ Department of Chemistry and Biochemistry and the Cooperative Institute for Research in the Environmental Sciences, \\ University of Colorado, Boulder, CO 80309, USA
}

Received: 26 June 2008 - Published in Atmos. Chem. Phys. Discuss.: 11 August 2008

Revised: 27 January 2009 - Accepted: 3 February 2009 - Published: 4 March 2009

\begin{abstract}
Cirrus clouds are composed of ice particles and their formation pathways have been studied extensively in the laboratory. The ability of ammonium sulfate particles to act as nuclei for cirrus clouds has been of particular importance because of their ubiquitous presence in the upper troposphere. The results of past laboratory experiments of homogeneous ice nucleation from ammonium sulfate particles show a wide range of freezing conditions. In the present study, a flow tube apparatus equipped with Fourier transform infrared spectroscopy was used to reexamine these discrepancies. It was found that when ammonium sulfate particles were preconditioned at $100 \%$ relative humidity $(\mathrm{RH})$ prior to experimentation, the particles began to freeze at conditions predicted by the homogeneous ice nucleation model developed by Koop et al. (2000). If the particles were not preconditioned at $100 \% \mathrm{RH}$, some froze at warmer temperatures and lower ice saturation ratios than predicted by Koop et al. (2000). It is hypothesized that a population of effloresced particles affected freezing conditions for particles that were not preconditioned at $100 \% \mathrm{RH}$.
\end{abstract}

\section{Introduction}

Cirrus cloud formation is largely controlled by the nucleation potential of the aerosol particles available in the upper troposphere. The ability of individual particles to nucleate ice depends directly on their microphysical and chemical properties. Because sulfate particles are ubiquitous in the upper

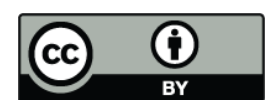

Correspondence to: M. A. Tolbert (tolbert@cires.colorado.edu) troposphere (Murphy et al., 1998), their ability to nucleate ice has been extensively studied.

As discussed by Abbatt et al. (2006) many experiments have been performed to determine the conditions at which ice homogeneously nucleates from ammonium sulfate particles. Ice supersaturation $\left(S_{i c e}\right)$ values found by studies using solid substrates or emulsions, i.e. Bertram et al. (2000) and Koop et al. (1999), generally agree with each other and are consistent with the homogeneous ice nucleation model developed by Koop et al. (2000). In contrast, those studies performed with freely floating deliquesced ammonium sulfate particles (i.e., (Chen et al., 2000; Chelf and Martin, 2001; Cziczo and Abbatt, 1999; Hung et al., 2002; Prenni et al., 2001; Wise et al., 2004) show a wide range of freezing conditions which generally do not agree with the homogeneous ice nucleation model developed by Koop et al. (2000).

Because accurate climate modeling requires a complete understanding of cirrus cloud formation mechanisms, these discrepancies should be resolved. It has been hypothesized that factors such as methods used to determine solution concentration, particle size, particle size distributions, residence times, and fraction of particles frozen contribute to differences in the ammonium sulfate freezing temperatures observed. Hung and Martin (2001) suggested that the major discrepancies can be resolved by considering the number of freezing events occurring. However, Hung and Martin (2001) also found that no volume nucleation rate function exists that can reconcile all experimental results.

Abbatt et al. (2006) showed that laboratory measurements support an ice nucleation pathway by depositional ice nucleation onto solid ammonium sulfate aerosol particles. Using a cloud chamber, they found that solid ammonium sulfate particles (formed at less than $10 \% \mathrm{RH}$ ) were efficient ice nucleators (onset $S_{\text {ice }}=1.20$ at $221 \mathrm{~K}$ ). In this experiment, Abbatt

Published by Copernicus Publications on behalf of the European Geosciences Union. 
et al. (2006) inferred the presence of solid ammonium sulfate particles because of the conditions under which they were produced. A similar ice nucleation experiment using a cloud chamber was conducted by Mangold et al. (2005). They found that the onset of ice nucleation occurred for ammonium sulfate particles in the range of $1.2<\mathrm{S}_{\text {ice }}<1.27$ (temperatures between 197 and $221 \mathrm{~K}$ ). Although FTIR spectroscopy showed that the majority of the ammonium sulfate particles were supercooled solutions at these conditions, the presence of a small fraction of effloresced particles could not be ruled out. Therefore, it was thought that a small fraction of effloresced particles acted as heterogeneous ice nuclei at low $S_{\text {ice }}$ values.

In addition to the cloud chamber studies, Abbatt et al. (2006) directly studied the ice nucleating ability of effloresced ammonium sulfate particles deposited on a hydrophobic support. These experiments showed that, depending on the preparation method, solid ammonium sulfate acted as efficient ice nuclei. In agreement with Abbatt et al. (2006), Shilling et al. (2006) showed that 1 in $1 \times 10^{5}$ solid ammonium sulfate particles deposited on a plate acted as ice nuclei at $S_{\text {ice }}$ values lower than that predicted for homogeneous nucleation.

The present manuscript provides data that helps resolve discrepancies between ice nucleation experiments performed using freely flowing ammonium sulfate particles and particles supported by substrates. Ice nucleation experiments are performed on aqueous ammonium sulfate droplets that have preconditioned using different methods, with reproducible but different results depending on conditioning method.

\section{Experimental}

\subsection{Flow tube system}

The flow tube system used to measure homogeneous ice nucleation in deliquesced ammonium sulfate particles was similar to that used in Wise et al. (2004) and in Prenni et al. (2001). However, the experimental procedure was modified in this study. Therefore, a description of the flow tube system (Fig. 1) and experimental procedure are given here.

Ammonium sulfate particles were generated by feeding an ammonium sulfate solution (ranging from 10-20 wt \%) at $0.2 \mathrm{ml} / \mathrm{min}$ into an atomizer (TSI 3076) using a Harvard apparatus syringe pump. After atomization, the deliquesced particles were passed over conditioning baths (at room temperature) with a variety of different compositions depending on the type of experiment conducted. For some experiments, the particles were passed over conditioning baths such as pure water and sulfuric acid solutions. In addition to these baths, other solutions such as a saturated ammonium nitrate solution ( $60 \% \mathrm{RH}$, (Martin, 2000)) and an ammonium nitrate/sodium chloride solution at the eutonic compo-

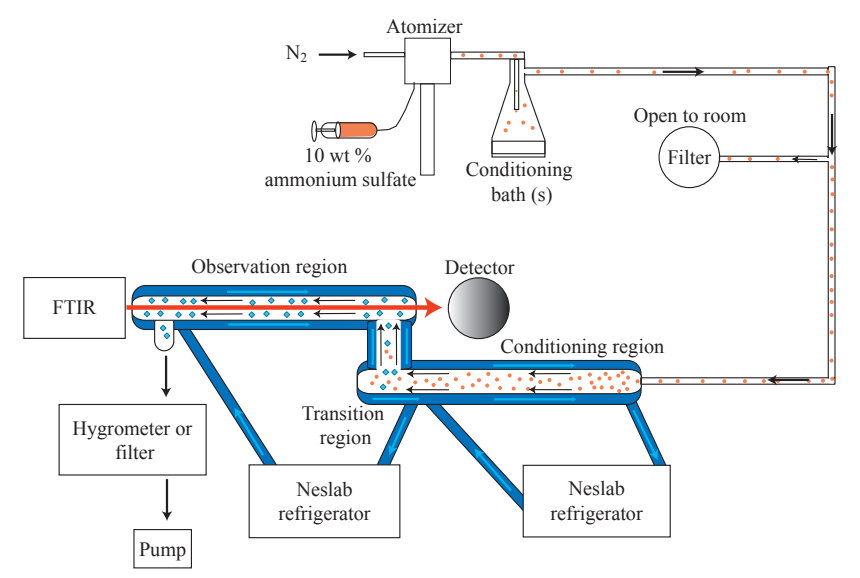

Fig. 1. Experimental setup used for measuring ice nucleation. Ammonium sulfate particles were generated using a TSI atomizer, were passed over conditioning baths, and entered a series of temperature controlled flow tubes. The first set of flow tubes were covered with ice. The water vapor pressure created by the ice was used to set aerosol composition for the homogeneous nucleation experiments and was used to create a supersaturation of water vapor for the depositional nucleation experiments. Ice nucleation was measured using Fourier transform infrared spectroscopy (FTIR) in the observation region. At the onset of depositional ice nucleation, the particle flow was stopped and water vapor pressure was measured using a chilled mirror hygrometer. For all other experiments a filter was used to remove particles prior to entering the pump.

sition ( $40 \% \mathrm{RH}$; Martin, 2000) were used to precondition the aerosol particles (see Sect. 2.2 below).

Following the preconditioning baths, the particles passed through a series of jacketed flow tubes at $\sim 3.5 \mathrm{~L} / \mathrm{min}$. The flow tubes were cooled using recirculating flows of methanol from two Neslab refrigerators. The first series of flow tubes will be referred to as the conditioning region and were cooled to temperatures ranging from $-5^{\circ} \mathrm{C}$ to $-40{ }^{\circ} \mathrm{C}$. Each day, distilled water was added to the conditioning region thus coating the bottom of the tube walls with ice. The amount of water vapor in the conditioning region was set by the temperature of the region and was determined using ice vapor pressure measurements from Marti and Mauersberger (1993). In addition, the water partial pressure in the conditioning region was directly measured using a CR-1A chilled mirror hygrometer (Buck Research Instruments, L.L.C., sample flow rate $\sim 3.5 \mathrm{~L} / \mathrm{min}$ ). During homogeneous ice nucleation experiments, the conditioning region was used to set the composition of the deliquesced ammonium sulfate particles entering it. If the particles in the conditioning region were in equilibrium with the water vapor at that temperature, the particles had a well-defined composition and water activity.

Ice nucleation occurred in the observation region and was detected using FTIR transmission spectroscopy. It should be noted that a small fraction of particles freezing can manifest as a large ice signal in the FTIR spectra. The junction 
between the conditioning tube and the observation tube is termed the transition region, and was cooled (by separate Neslab refrigerators) on one end at the observation temperature and on the other end at the conditioning temperature. Because the temperature drop from the conditioning to the observation region occurred in this transition region, the aerosol particles had time to reach the observation temperature before being monitored using FTIR spectroscopy. When the temperature was dropped in the observation region and no ice formed, particle composition remained the same (i.e., the IR spectrum did not change).

Temperature was measured using thermistors placed at the cold end of the conditioning region and the middle of the observation region. Specifically, the thermisor placed in the conditioning region was frozen into the ice coating the bottom of the flow tube and the thermistor placed in the observation region was placed in the aerosol particle flow. Each thermistor was calibrated against a reference temperature measurement to $\pm 0.20 \mathrm{~K}$ over the temperature range studied.

\subsection{Determination of aqueous particle composition and wa-} ter activity

The aqueous composition of pure ammonium sulfate particles was determined using two separate methods. When the aerosol particles were in equilibrium with the temperature and water vapor in the ice coated conditioning region, particle composition was calculated using the Aerosol Inorganics Model (AIM method, (Clegg et al., 1998a, b, 2000); available at http://www.aim.env.uea.ac.uk/aim/aim.php). Particle composition was also determined directly from collected infrared spectra (IR method) using the composition calibration curve constructed by Chelf and Martin (2001). Using the IR method, the particles did not need to be in equilibrium with the temperature and water vapor in the ice coated conditioning region. Particle composition calculated using the IR method was also used to determine particle water activity. Specifically, particle composition prior to the formation of ice was used in conjunction with the AIM model (at the observation region temperature) to calculate water activity.

Wise et al. (2004) used a similar flow tube apparatus to study homogeneous ice nucleation from aqueous ammonium sulfate and mixed ammonium sulfate/dicarboxylic acid particles. The temperature at which homogeneous ice nucleation occurred was dependent on the composition of the aerosol particles. Therefore, Wise et al. (2004) took great care to match the ammonium sulfate composition determined using the AIM method with the composition determined using the IR method. Because the conditioning region of the flow tube apparatus had a finite length, gas phase water had to be removed from the atomized particles in order for the particles to attain equilibrium with water vapor in the conditioning region. Wise et al. (2004) removed gas phase water by passing the aerosol particles over sulfuric acid baths.
In the present study, gas phase water was also removed from the particles using various types of conditioning baths. However, the conditioning baths were arranged in two different configurations. In the first configuration, a water bath (100\% RH) was used to precondition the aerosol particles exiting the atomizer. This ensured that all the particles were liquid. Following the water bath the particles were passed over a secondary bath. The secondary bath was either a saturated ammonium nitrate solution $(\sim 60 \% \mathrm{RH})$, an ammonium nitrate/sodium chloride solution at the eutonic composition $(\sim 40 \% \mathrm{RH})$, or a $48 \mathrm{wt} \%$ sulfuric acid bath $(\sim 40 \%$ $\mathrm{RH})$. The secondary baths were used to reduce gas phase water, but did not remove enough water vapor to effloresce the particles. It was found that the secondary baths did not remove enough gas phase water to allow the particles to attain equilibrium with the water vapor in the conditioning region. Therefore, the composition determined using the IR method and the AIM method were not the same prior to ice nucleation. In this case, the IR method was used to determine particle composition and water activity. In the second configuration, sulfuric acid baths ranging in composition from $35 \%$ to $98 \%$ ( $50 \%$ to $<10 \% \mathrm{RH}$ ) were used to precondition the aerosol particles exiting the atomizer. Using these sulfuric acid baths, the composition of the ammonium sulfate particles determined using the IR method and the AIM method were approximately the same prior to ice nucleation. The two conditioning bath configurations were chosen to test the hypothesis that a fraction of solid ammonium sulfate particles affect ice nucleation.

\subsection{Determination of homogeneous ice nucleation}

At the beginning of an ice nucleation experiment, an infrared spectrum was taken at a temperature well above the freezing temperature to ensure that no ice was present in the particles. At this temperature, particle composition was determined using the IR method and recorded. The temperature of the observation region was then incrementally cooled while keeping the conditioning region at a constant temperature. Because the conditioning region was maintained at a constant temperature, the water partial pressure the particles experienced in the conditioning region remained the same. Therefore, prior to the onset of freezing, the particle composition remained approximately the same. In order to confirm that particle composition remained the same as the observation tube temperature was lowered, the composition of the aerosol particles was monitored using FTIR spectroscopy at each temperature.

At the freezing point, several changes occurred in the infrared spectrum of the particles. The $\mathrm{OH}$-stretching region, which has a maximum at $\sim 3300 \mathrm{~cm}^{-1}$ for liquid solutions (Hung et al., 2002) shifted to lower frequencies and the $\mathrm{H}_{2} \mathrm{O}$ stretch centered at $\sim 800 \mathrm{~cm}^{-1}$ shifted to higher frequencies. At the onset of homogeneous ice nucleation, the changes in the IR spectra were visually subtle. However, the onset of 


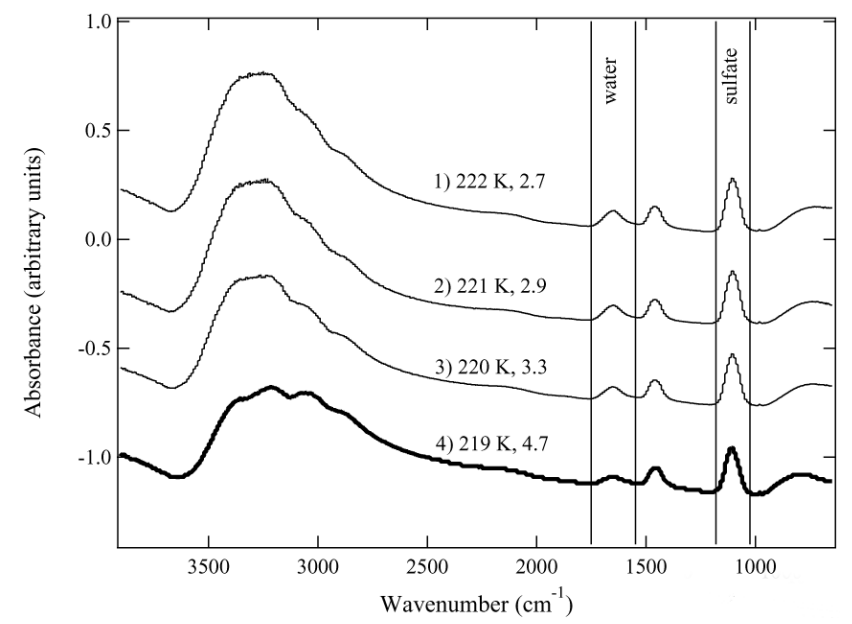

Fig. 2. IR spectra of aqueous ammonium sulfate particles (preconditioned using a distilled water bath) as the temperature was dropped in the observation region from $222 \mathrm{~K}$ to $219 \mathrm{~K}$. The onset of ice nucleation occurred at $219 \mathrm{~K}$ and caused a substantial increase in the sulfate to water peak area ratio (4.7, peaks highlighted with vertical lines). The spectrum in which ice is present is denoted with a thicker line and all spectra are offset for clarity.

freezing was apparent when the peak area ratio of the sulfate band $\left(1180 \mathrm{~cm}^{-1}\right.$ to $\left.1025 \mathrm{~cm}^{-1}\right)$ to the integrated water band $\left(1751 \mathrm{~cm}^{-1}\right.$ to $\left.1549 \mathrm{~cm}^{-1}\right)$ was monitored. When the particles began to freeze, the area of the integrated water band decreased. Thus, the peak area ratio increased substantially. When the peak area ratio changed by a substantial amount the particles had begun to freeze. If the temperature in the observation region was dropped $1^{\circ} \mathrm{C}$ past the onset temperature, ice features in IR spectrum were visibly apparent.

\subsection{Determination of critical ice saturation ratios $\left(\mathrm{S}_{\mathrm{ice}}\right)$}

A parameter widely used in cloud microphysical models is the temperature dependent critical ice saturation ratio, $S_{\text {ice }}$, which is defined as:

$S_{\text {ice }}=P_{\mathrm{H}_{2} \mathrm{O}} / \mathrm{VP}(T$, ice $)$

where $P_{\mathrm{H}_{2} \mathrm{O}}$ is the water partial pressure at the freezing temperature and VP $(T$, ice) is the vapor pressure of water over ice at the same temperature. Prior to the onset of homogeneous nucleation, particle composition (determined using the IR method) was used to calculate particle water activity (determined using the AIM model). Particle water activity in turn set $P_{\mathrm{H}_{2} \mathrm{O}}$. Using the temperature of the observation region, VP $(T$, ice) was calculated using measurements from Marti and Mauersberger (1993). $S_{\text {ice }}$ was then calculated.

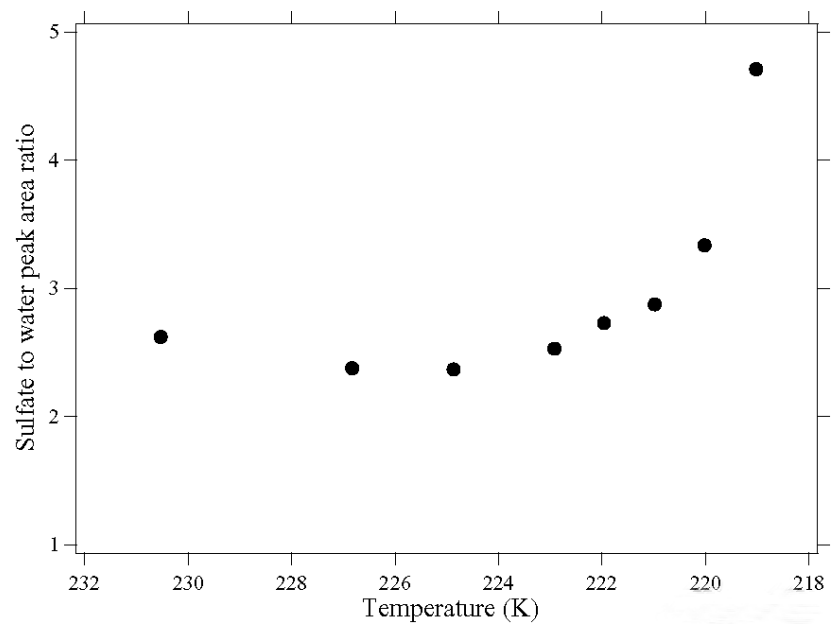

Fig. 3. Sulfate to water peak area ratio versus temperature for the homogeneous ice nucleation experiment described in Fig. 2. At $219 \mathrm{~K}$, a significant increase in the peak area ratio occurred which signaled the onset of ice formation.

\section{Results and discussion}

3.1 Ice nucleation in aqueous ammonium sulfate particles

Figure 2 presents IR spectra recorded during an ice nucleation experiment. In this type of experiment the aerosol particles were preconditioned using a distilled water bath followed by an ammonium nitrate/sodium chloride solution at the eutonic composition. In this figure, spectral data are shown when the aqueous ammonium sulfate particles were cooled from $222 \mathrm{~K}$ (spectrum 1) to $219 \mathrm{~K}$ (spectrum 4) in the observation region while holding the conditioning region at a constant $243 \mathrm{~K}$.

Prior to flowing particles into the experimental apparatus, the water partial pressure in the conditioning region was measured with the chilled mirror hygrometer. It was found that there was good agreement in the water partial pressure measured with the hygrometer and the water partial pressure determined using ice vapor pressure measurements from Marti and Mauersberger (1993) at 243 K. Once this check was completed, the homogeneous ice nucleation experiment was started.

At $222 \mathrm{~K}$ no ice was observed in the infrared spectrum and the ammonium sulfate concentration was calculated to be $\sim 28 \mathrm{wt} \%$ using the IR method. In addition to monitoring the concentration of the particles, the peak area ratio of the sulfate band to the integrated water band was recorded. At $222 \mathrm{~K}$ the ratio was found to be $\sim 2.7$. When the temperature in the observation region was dropped to $220 \mathrm{~K}$, the peak area ratio was similar to the ratio obtained at $222 \mathrm{~K}$. At $219 \mathrm{~K}$ a large increase in the peak area ratio was observed.

In order to illustrate the determination of the onset of freezing, a plot of the ratio of the sulfate band to the 


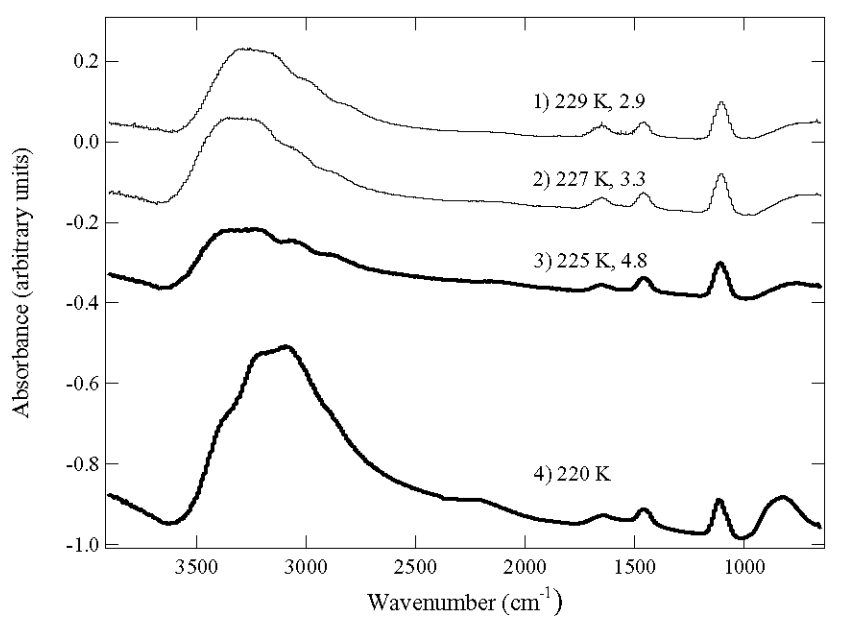

Fig. 4. IR spectra of aqueous ammonium sulfate particles (preconditioned using 98 and $45 \mathrm{wt} \%$ sulfuric acid baths) as the temperature was dropped in the observation region from $229 \mathrm{~K}$ to $220 \mathrm{~K}$. The onset of ice nucleation occurred at $225 \mathrm{~K}$ and caused a substantial increase in the sulfate to water peak area ratio (4.8). As the temperature of the observation region was dropped to $220 \mathrm{~K}$, ice features became more prominent. The spectra in which ice is present are highlighted with thicker lines and all spectra are offset for clarity.

integrated water band is shown in Fig. 3. The data points correspond to the data points in Fig. 2, with the addition of several peak area ratios at warmer observation region temperatures than $222 \mathrm{~K}$. Between $232 \mathrm{~K}$ and $220 \mathrm{~K}$, the peak ratios fluctuated between 2.3 and 3.3. A significant increase in the peak area ratio was not observed until the observation tube temperature reached $219 \mathrm{~K}$. At this temperature a population of the particles froze.

Figure 4 is an example of the IR spectra obtained during the second type of ice nucleation experiment. In this particular experiment, a $98 \mathrm{wt} \%$ sulfuric acid bath followed by a $45 \mathrm{wt} \%$ sulfuric acid bath (RH $\sim 46 \%$ ) were used to precondition the aerosol particles after they were generated with the atomizer. These conditions mirror those used in Wise et al. (2004) and were chosen to test for consistency over the intervening years. Spectral data were obtained when the aqueous ammonium sulfate particles were cooled from $229 \mathrm{~K}$ (spectrum 1) to $220 \mathrm{~K}$ (spectrum 4) in the observation region while holding the conditioning region at a constant $261 \mathrm{~K}$.

At $229 \mathrm{~K}$ no ice was observed in the infrared spectrum and the ammonium sulfate concentration in the particle was calculated to be $\sim 29 \mathrm{wt} \%$ using the IR method. The concentration of ammonium sulfate (assuming that the particles were in equilibrium with the water vapor in the conditioning region) calculated using the AIM method was $\sim 31 \mathrm{wt} \%$. Therefore, the particles in this experiment had approximately the same composition as the previous experiment. In addition, the assumption that the sulfuric acid baths removed enough gas phase water to allow the particles to attain equilibrium with the water vapor in the conditioning region was

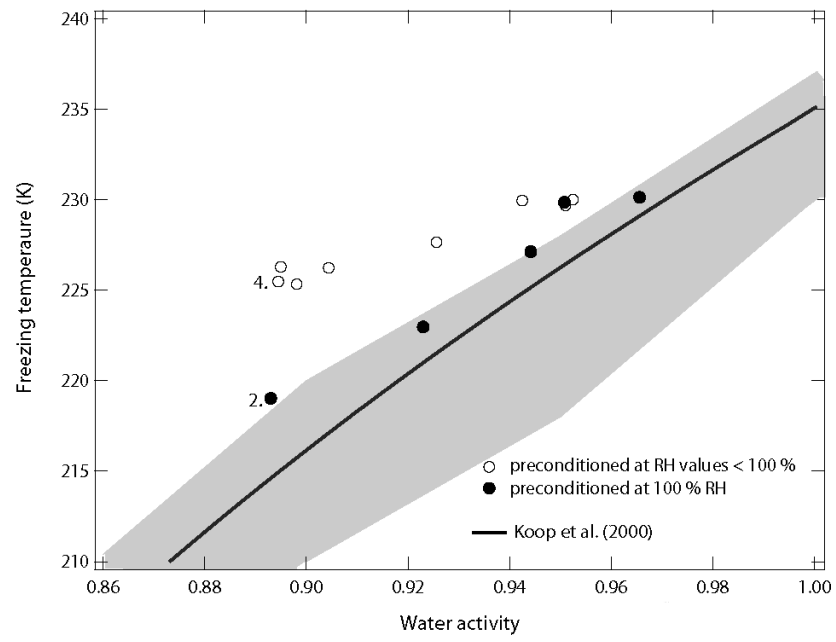

Fig. 5. Freezing temperature versus water activity for ammonium sulfate particles preconditioned at RH values $<100 \%$ (open circles) and preconditioned at $100 \%$ RH (filled circles). For comparison, freezing temperatures predicted using the water activity based nucleation theory developed by Koop et al. (2000) are shown as a solid line. The spread in the data points used to construct the solid line is represented by the shaded area. The IR spectra shown in Fig. 2 were used to produce the point highlighted with the "2" and the IR spectra shown in Fig. 4 were used to produce the point highlighted with the "4".

valid. Similar to the previous experiment, the peak ratio of the sulfate band to the integrated water band was monitored. At $229 \mathrm{~K}$ the ratio was found to be $\sim 2.9$. The spectrum obtained when the observation region was cooled to $225 \mathrm{~K}$ shows a peak area ratio substantially greater than at previous temperatures. Therefore, a population of particles froze at $225 \mathrm{~K}$. As the temperature in the observation region was dropped to $220 \mathrm{~K}$, the IR spectrum of ice was apparent.

The only difference in the experimental setup for the freezing data recorded in Figs. 2 and 4 were the configurations of the preconditioning baths. Namely, the aerosol particles shown in Fig. 2 were preconditioned at 100\% RH while the particles shown in Fig. 4 were not. It is apparent that the onset of freezing occurred at a warmer temperature for the particles that were not preconditioned with the water bath prior to entering the flow tube apparatus. In order to determine if this difference was systematic, multiple ice nucleation experiments were performed using each preconditioning bath configuration. The results of these experiments are shown in Fig. 5.

Figure 5 is a plot of temperatures at which the onset of freezing occurred versus water activity for aqueous ammonium sulfate particles. The filled circles represent temperatures at which ice nucleated in particles that were preconditioned at RH values equal to $100 \%$. The open circles represent temperatures at which ice nucleated in particles that were preconditioned at $\mathrm{RH}$ values $<100 \%$. As the particles 
became more concentrated in ammonium sulfate (lower water activity), they froze at progressively lower temperatures. Over the range of water activities studied, the particles preconditioned at $100 \% \mathrm{RH}$ froze at systematically lower temperatures than particles preconditioned at RH values $<100 \%$.

The particles preconditioned at $\mathrm{RH}$ values $<100 \%$ appear to freeze at substantially warmer temperatures than what would be predicted using the water activity based nucleation theory developed by Koop et al. (2000) (represented with a solid line in Fig. 5). This result is consistent with other groups employing a flow tube apparatus to study homogeneous ice nucleation in ammonium sulfate particles (i.e., Cziczo and Abbatt, 1999 and Wise et al., 2004). The particles preconditioned at $100 \% \mathrm{RH}$ also appear to supercool somewhat less than what would be predicted using the water activity based nucleation theory. However, the freezing data with which Koop et al. (2000) used to construct the line shown in Fig. 5 does have substantial spread. The shaded area in Fig. 5 represents an estimation of the range in freezing data presented by Koop et al. (2000). The freezing conditions for particles preconditioned at $100 \% \mathrm{RH}$ are close to the Koop et al. (2000) freezing data within error. In addition, many of the data points in Koop et al. (2000) represent median freezing temperatures rather than the onset of freezing reported here. Therefore, the temperatures at which ice formed from ammonium sulfate particles preconditioned at $100 \% \mathrm{RH}$ are consistent with the Koop et al. (2000) water activity based nucleation theory.

Prior to freezing, the ammonium sulfate particles for all experiments presented in Fig. 5 appear to be deliquesced using the IR spectra. Therefore, the water activity of the particles should constrain the freezing temperature according to the Koop et al. (2000) homogeneous ice nucleation model. Obviously, the ammonium sulfate particles preconditioned at RH values less than $100 \%$ do not agree well with the Koop et al. (2000) model while the particles preconditioned at $100 \%$ RH do agree.

A possible explanation for the differing results is that the ammonium sulfate particles conditioned at less than $100 \%$ RH has a small population of solid particles. A similar hypothesis was put forth by Abbatt et al. (2006). Using a cloud chamber, Abbatt et al. (2006) (supplemental materials) performed ice nucleation experiments in which the average $\mathrm{RH}$ in the cloud chamber was not low enough to effloresce the particles. In these experiments, two distinct modes of ice nucleation were observed. The first mode of ice nucleation was observed at an $\mathrm{S}_{\text {ice }}$ value of 1.15 (at $223 \mathrm{~K}$ ) and the second mode was observed at an $S_{\text {ice }}$ value of 1.55 . It was hypothesized that portions of the air in the cloud chamber were dryer than that of the average value. It was concluded that some of the particles effloresced and nucleated ice at the low $\mathrm{S}_{\text {ice }}$ value of 1.15 while the remainder of the particles (deliquesced) nucleated ice at the higher $S_{\text {ice }}$ value of 1.55 (in agreement with that predicted by Koop et al., 2000).
In addition to Abbatt et al. (2006), Hung et al. (2002) studied the conditions at which ice nucleation occurred in aqueous ammonium sulfate particles when a dry ammonium sulfate particle stream was added. Hung et al. (2002) found that aqueous ammonium sulfate particles showed a deeper supercooling than the mixed aqueous/solid ammonium sulfate particles. Hung et al. (2002) used the IR method to determine the composition of their particles. Because the IR method is only valid for deliquesced particles, Hung et al. (2002) attributed the differences in freezing conditions to erroneous concentration determinations.

In the freezing experiments presented here, it is possible that a fraction of the particles effloresced after being generated using the atomizer. Furthermore, it is possible that a fraction of the particles effloresced after being exposed to RH values less than $35 \%$ in certain sulfuric acid conditioning baths. Therefore, if the particles were not passed over the $100 \%$ RH bath, the effloresced particles might be responsible for ice nucleation at temperatures warmer than predicted using the Koop et al. (2000) model or for erroneous concentration determinations using the IR method.

Wise et al. (2004) had concerns that solid ammonium sulfate particles were present in the flow tube system. However, they found that when the atomized ammonium sulfate particles were cooled below the para- to ferroelectric phase transition $(223 \mathrm{~K})$ no distinct changes in the infrared spectrum occurred. Furthermore, they found that the asymmetric $1420 \mathrm{~cm}^{-1}$ ammonium peak, which indicates the presence of solid ammonium sulfate, was not present in the IR spectra. In contrast to Hung et al. (2002), Wise et al. (2004) concluded that solid ammonium sulfate particles were not affecting their determination of ammonium sulfate composition or freezing conditions. This conclusion appears to be at odds with the hypothesis presented above for the differences in freezing temperatures. However, it is possible that not enough particles effloresce when exiting the atomizer to allow the signatures of solid ammonium sulfate to appear in the IR spectra prior to ice nucleation.

\subsection{Comparison of freezing conditions with previous stud- ies}

A variety of experimental procedures have been used to determine $S_{\text {ice }}$ as a function of freezing temperature for different modes of ice nucleation from ammonium sulfate particles. The results of the studies presented in Abbatt et al. (2006) (Fig. 1b) are plotted in Fig. 6 along with the new data determined here. The solid symbols in Fig. 6 signify freezing conditions for homogeneous ice nucleation and the open symbols correspond to freezing conditions for depositional ice nucleation. The thick solid line in Fig. 6 represents the homogeneous ice nucleation model developed by Koop et al. (2000) and the thin solid line is an $S_{\text {ice }}$ of 1. 


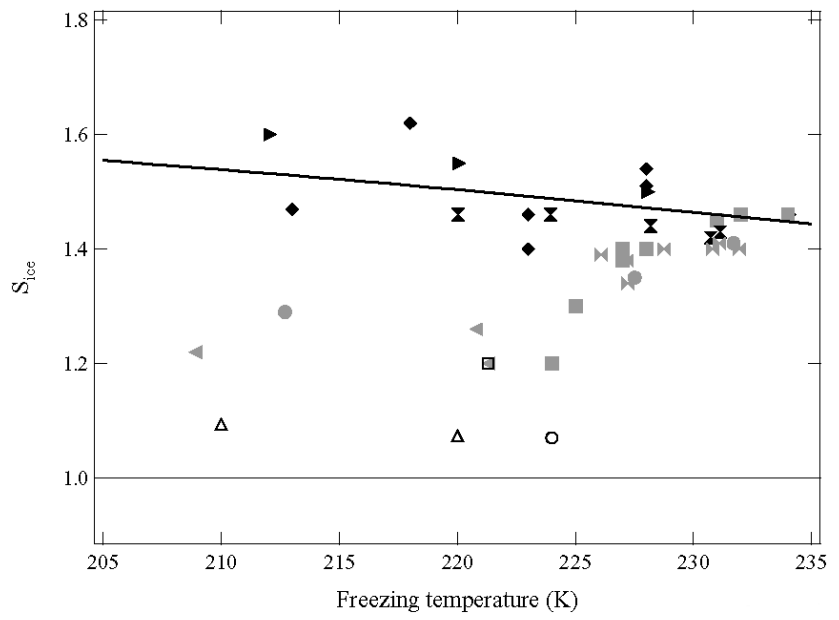

Fig. 6. Ice saturation ratio $\left(S_{\text {ice }}\right)$ as a function of freezing temperature for ammonium sulfate particles (adapted from Abbatt et al., 2006). The solid symbols represent conditions for homogeneous ice nucleation: Cziczo and Abbatt (1999) (squares); Wise et al. (2004) (circles); Bertram et al. (2000) (right pointing triangles); Chen et al. (2000) (1\% freezing, diamonds); Mangold et al. (2005) (left pointing triangles). The bowties represent conditions for the ice nucleation experiments presented in Fig. 5 of this study: preconditioned at $100 \% \mathrm{RH}$ (vertical bowties); preconditioned at $<100 \%$ (horizontal bowties). The open symbols represent conditions for depositional nucleation: Abbatt et al. (2006) (hydrophobic support, circles); Abbatt et al. (2006) (particles formed at less than 10\% RH in a cloud chamber, square); Shilling et al. (2006) (hydrophobic support, triangles). Grey shaded symbols denote experiments in which ice nucleation could have been affected by depositional ice nucleation and the solid black symbols correspond to experiments in which all particles were fully deliquesced. The thick solid line represents the homogeneous ice nucleation model developed by Koop et al. (2000) and the thin solid line is an $S_{\text {ice }}$ of 1.

Literature values of $S_{\text {ice }}$ for the homogeneous nucleation of ice in ammonium sulfate particles range from $\sim 1.2$ to 1.6 at freezing temperatures from 205 to $235 \mathrm{~K}$. In addition to the wide spread in experimental conditions in which ice nucleated from the particles, some of the experimental results are at odds with the homogeneous ice nucleation model developed by Koop et al. (2000) while others are not. Abbatt et al. (2006) provided a detailed discussion for the discrepancies in freezing conditions for ammonium sulfate particles.

The ice nucleation experiments presented in the literature and in this study can be divided into two separate categories. The first category encompasses experiments in which it is possible that a fraction of the particles are effloresced. The fraction of effloresced particles provides heterogeneous ice nuclei which causes a wide range of freezing conditions. The experiments in which heterogeneous ice nuclei could be present are denoted in Fig. 6 with grey shaded symbols. The horizontal bowties represent $S_{\text {ice }}$ calculated (using the AIM model) for ammonium sulfate particles preconditioned at $\mathrm{RH}$ values $<100 \% \mathrm{RH}$ in this work. The squares denote $\mathrm{S}_{\text {ice }}$ values determined by Cziczo and Abbatt (1999). Cziczo and Abbatt (1999) used a flow tube apparatus similar to the one used in this manuscript. Therefore it is likely that solid ammonium sulfate particles were produced during their particle production or conditioning processes. Finally, the left pointing triangles represent $S_{\text {ice }}$ values calculated by Mangold et al. (2005) using an aerosol chamber. Similar to the flow tube experiments, the aerosol chamber could contain pockets of air in which aqueous ammonium sulfate particles effloresce. The $S_{\text {ice }}$ values determined by this category of experiments do not agree well with Koop et al. (2000) and are highly variable.

The second category of ice nucleation experiments encompasses experiments in which in which all the particles are fully deliquesced (black symbols in Fig. 6). In this study, ammonium sulfate particles preconditioned at $100 \% \mathrm{RH}$ (vertical bowties) are fully deliquesced prior to ice nucleation. The right pointing triangles correspond to $S_{\text {ice }}$ values determined by Bertram et al. (2000). Bertram et al. (2000) employed differential scanning calorimetry of emulsified ammonium sulfate solutions and optical microscopy of aqueous ammonium sulfate solutions to study ice nucleation. Finally, Chen et al. (2000) use a thermal gradient diffusion chamber for their ice nucleation studies. It can be seen in Fig. 6 that $S_{\text {ice }}$ values determined by this category of experiments do agree well with Koop et al. (2000). Further, there is much less scatter in the data between various experiments.

\section{Conclusions}

Two different types of ice nucleation experiments were performed using ammonium sulfate particles in the flow tube apparatus. In the first type of experiment, a water bath $(100 \%$ $\mathrm{RH})$ was first used to precondition the aerosol particles exiting the atomizer. Following the water bath the particles were passed over a secondary bath which reduced gas phase water, but did not remove enough water vapor to effloresce the particles. Thus all particles entering the flow tube system were deliquesced. In the second type of experiment, sulfuric acid baths ranging in composition from 35 to 98 weight percent sulfuric acid $(50 \%$ to $<10 \% \mathrm{RH})$ were used to precondition the aerosol particles exiting the atomizer. Although effloresced particles were not detected in the IR spectra, it was inferred that the preconditioning baths in this configuration did effloresce some particles.

Different freezing conditions were realized depending on the type of ice nucleation experiment performed. It was found that when the particles were not conditioned with a water bath, ice nucleated at warmer temperatures and lower

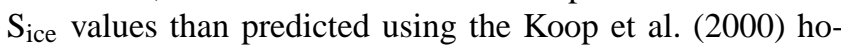
mogeneous ice nucleation model. Conversely, when the particles were fully deliquesced, ice nucleated at temperatures

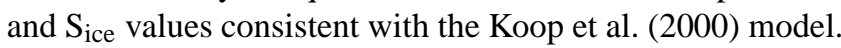


Acknowledgements. The authors gratefully acknowledge financial support from the National Science Foundation through grant NSF ATM 0650023. K. Baustian also received support from a NASA fellowship (NASA NNX08AU77H).

Edited by: D. Cziczo

\section{References}

Abbatt, J. P. D., Benz, S., Cziczo, D. J., Kanji, Z., Lohmann, U., and Mohler, O.: Solid ammonium sulfate aerosols as ice nuclei: A pathway for cirrus cloud formation, Science, 313, 1770-1773, 2006.

Bertram, A. K., Koop, T., Molina, L. T., and Molina, M. J.: Ice formation in $\left(\mathrm{NH}_{4}\right)_{2} \mathrm{SO}_{4}-\mathrm{H}_{2} \mathrm{O}$ particles, J. Phys. Chem. A, 104, 584-588, 2000.

Chelf, J. H. and Martin, S. T.: Homogeneous ice nucleation in aqueous ammonium sulfate aerosol particles, J. Geophys. Res., 106, 1215-1226, 2001.

Chen, Y., DeMott, P. J., Kreidenweis, S. J., Rogers, D. C., and Sherman, D. E.: Ice formation by sulfate and sulfuric acid aerosol particles under upper tropospheric conditions, J. Atmos. Sci., 57, 3752-3766, 2000.

Clegg, S. L., Brimblecombe, P., and Wexler, A. S.: A thermodynamic model of the system $\mathrm{H}^{+}-\mathrm{NH}_{4}^{+}-\mathrm{SO}_{4}^{2-}-\mathrm{NO}_{3}^{-}-\mathrm{H}_{2} \mathrm{O}$ at tropospheric temperatures, J. Phys. Chem. A, 102, 2137-2154, 1998a.

Clegg, S. L., Brimblecombe, P., and Wexler, A. S.: A thermodynamic model of the system $\mathrm{H}^{+}-\mathrm{NH}_{4}^{+}-\mathrm{Na}^{+}-\mathrm{SO}_{4}^{2-}-\mathrm{NO}_{3}^{-}-\mathrm{Cl}^{-}$$\mathrm{H}_{2} \mathrm{O}$ at $298.15 \mathrm{~K}$, J. Phys. Chem. A, 102, 2155-2171, 1998b.

Clegg, S. L., Brimblecombe, P., and Wexler, A. S.: Aerosol inorganics model, http://www.aim.env.uea.ac.uk/aim/aim.php, 2000.

Cziczo, D. J. and Abbatt, J. P. D.: Deliquescence, efflorescence, and supercooling of ammonium sulfate aerosols at low temperature: Implications for cirrus cloud formation and aerosol phase in the atmosphere, J. Geophys. Res., 104, 13781-13790, 1999.
Hung, H. and Martin, S.: Apparent freezing temperatures modeled for several experimental apparatus, J. Geophys. Res., 106, 20379-20394, 2001.

Hung, H., Malinowski, A., and Martin, S. T.: Ice nucleation kinetics of aerosols containing aqueous and solid ammonium sulfate particles, J. Phys. Chem. A, 106, 293-306, 2002.

Koop, T., Bertram, A. K., Molina, L. T., and Molina, M. J.: Phase transitions in aqueous nh4hso4 solutions, J. Phys. Chem. A, 103, 9042-9048, 1999.

Koop, T., Luo, B., Tsias, A., and Peter, T.: Water activity as the determinant for homogeneous ice nucleation in aqueous solutions, Nature, 406, 611-612, 2000.

Mangold, A., Wagner, R., Saathoff, H., Schurath, U., Giesemann, C., Ebert, V., Kramer, M., and Mohler, O.: Experimental investigation of ice nucleation by different types of aerosols in the aerosol chamber AIDA: Implications to microphysics of cirrus clouds, Meteorologische Zeitschrift, 14, 485-497, 2005.

Marti, J. and Mauersberger, K.: A survey and new measurements of ice vapor pressure at temperatures between 170 and $250 \mathrm{~K}$, Geophys. Res. Lett., 20, 363-366, 1993.

Martin, S. T.: Phase transitions of aqueous atmospheric particles, Chem. Rev., 100, 3403-3454, 2000.

Murphy, D. M., Thomson, D. S., and Mahoney, M. J.: In-situ measurements of organics, meteroric material, mercury, and other elements in aerosols at 5 to 19 kilometers, Science, 282, 16641669, 1998.

Prenni, A. J., Wise, M. E., Brooks, S. D., and Tolbert, M. A.: Ice nucleation in sulfuric acid and ammonium sulfate particles, J. Geophys. Res., 106, 3037-3044, 2001.

Shilling, J. E., Fortin, T. J., and Tolbert, M. A.: Depositional ice nucleation on crystalline organic and inorganic solids, J. Geophys. Res., 111, D12204, doi:10.1029/2003JD004313, 2006.

Wise, M. E., Garland, R. M., and Tolbert, M. A.: Ice nucleation in internally mixed ammonium sulfate/dicarboxylic acid particles, J. Geophys. Res., 109, D19203, doi:10.1029/2003JD004313, 2004. 